\title{
INFLUENCE OF SMEAR LAYER REMOVAL ON THE OBTURATION OF ROOT CANAL RAMIFICATIONS
}

\author{
Elaine Vianna Freitas FACHIN ${ }^{1}$, Roberta Kochenborger SCARPARO ${ }^{2}$, Liliane Inês Sachet MASSONI ${ }^{3}$
}

1- DDS, MSc, PhD, Associate Professor, Department of Conservative Dentistry, Dental School, Federal University of Rio Grande do Sul, Porto Alegre, RS, Brazil.

2- DDS, MSc, Substitute Professor, Department of Conservative Dentistry, Dental School, Federal University of Rio Grande do Sul, Porto Alegre, RS, Brazil.

3- DDS, MSc, Graduate Student, Department of Conservative Dentistry, Dental School, Federal University of Rio Grande do Sul, Porto Alegre, RS, Brazil.

Corresponding address: Dra. Elaine Vianna Freitas FACHIN - Universidade Federal do Rio Grande do Sul - Faculdade de Odontologia - Departamento de Odontologia Conservadora - Rua Ramiro Barcelos, 2492 - 90035-003 - Porto Alegre - RS - Brasil - e-mail: efachin@hotmail.com

Received: April 3, 2008 - Accepted: September 22, 2008

\begin{abstract}
Q

bjective: This study evaluated whether smear layer removal has any influence on the filling of the root canal system, by examining the obturation of lateral canals, secondary canals and apical deltas. Material and Methods: Eighty maxillary and mandibular canines were randomly divided into two groups, according to their irrigation regimen. Both groups were irrigated with $1 \% \mathrm{NaOCl}$ during canal shaping, but only the teeth in Group II received a final irrigation with 17\% EDTA for smear layer removal. The root canals were obturated with lateral condensation of gutta-percha and the specimens were cleared, allowing for observation under the microscope. Results: In Groups I and II, $42.5 \%$ and $37.5 \%$ of the teeth, respectively, presented at least one filled canal ramification. Although a larger number of obturated ramifications was found in Group I, there were no statistically significant differences between the two groups $(\mathrm{p}=0.4957)$. Conclusion: Smear layer removal under the conditions tested in this study did not affect the obturation of root canal ramifications when lateral condensation of gutta-percha was the technique used for root canal filling.
\end{abstract}

Key Words: Anatomy. Dental pulp cavity. EDTA. Endodontics. Root canal obturation. Smear layer.

\section{INTRODUCTION}

The clinical implication of the smear layer has not yet been fully understood. It has been described as a protection against bacteriological diffusion and penetration into the dentinal tubules ${ }^{8,10}$. Other authors ${ }^{9,12}$ consider that the presence of smear layer may prevent the endodontic filling material from penetrating into dentinal tubules and compromise its adhesion to the canal walls.

The importance of smear layer removal in achieving better root canal seal has been extensively investigated. Vivacqua-Gomes, et al. ${ }^{17}$ (2002) observed the influence of irrigants on the coronal microleakage of laterally condensed gutta-percha root fillings, and the best results occurred when $1 \% \mathrm{NaOCl}$ and $17 \%$ EDTA were used. On the other hand, Madison and Krell ${ }^{5}$ (1984) compared the effects of smear layer removal on the apical sealing of endodontically treated teeth and found no statistically significant differences between the groups irrigated with REDTA and $\mathrm{NaOCl}$. Furthermore, Saleh, et al. ${ }^{12}$ (2008) observed that the removal of smear layer did not prevent bacterial penetration along the root canal fillings.
Clearly, few studies correlate accessory canal filling to the presence or absence of smear layer. Goldberg, et al. ${ }^{3}$ (1986) evaluated in vitro the effects of different solutions (15\% EDTA, $5 \% \mathrm{NaOCl}$ and distilled water - control) used for root canal irrigation on the filling of lateral canals and observed that more lateral canals could be filled when $15 \%$ EDTA was used, with statistically significant difference when this group was compared to the other two.

With the purpose of evaluating the filling of accessory canals after different final irrigation regimens, Villegas, et al. ${ }^{16}$ (2002) examined cleared teeth obturated with either System B or Obtura II. The results showed no differences between the use of $6 \% \mathrm{NaOCl}$ alone and a $15 \%$ EDTA $/ 6 \%$ $\mathrm{NaOCl}$ combination. More recently, Bertacci, et al. ${ }^{2}$ (2007) compared different solutions used for irrigation regarding their influence on root canal system filling. They concluded that root canal ramification fillings could be obtained without using EDTA. There were no statistically significant differences regarding number, length and diameter of filled ramifications. The smear layer did not prevent the sealing of lateral canals.

Considering the lack of studies discussing this subject, 
the aim of this study was to evaluate in vitro the influence of smear layer removal on the filling of lateral canals, secondary canals and apical deltas in teeth prepared either using or not EDTA as a final irrigant and filled with lateral condensation of gutta-percha and an epoxy resin root canal sealer (AH Plus).

\section{MATERIAL AND METHODS}

Eighty extracted human canines were selected and stored in distilled water. Teeth with apical curvatures, resorption, more than one root or canal, and previous endodontically treated teeth were discarded.

The teeth were immersed in $1 \% \mathrm{NaOCl}$ for $12 \mathrm{~h}$ to eliminate root-adhered organic debris and calculi, immediately washed in running water, dried with absorbent paper and stored in glass vials numbered 1 to 80 containing saline.

Before canal shaping, the teeth were decoronated at the cementoenamel junction to eliminate possible variations during the surgical phase of canal access and instrumentation. After this, the teeth were randomly assigned to two groups of 40 roots each, according to the irrigation regimen used: Group I was irrigated with $1 \% \mathrm{NaOCl}$ and Group II was irrigated with $1 \% \mathrm{NaOCl}$ followed by irrigation with $17 \%$ EDTA. The solutions used for irrigation $(1 \%$ $\mathrm{NaOCl}$ and $17 \%$ EDTA) were delivered from $1.8 \mathrm{~mL}$ sterile plastic tubes in order to standardize the solution volume used in each root canal.

The root canals were emptied and explored using $\mathrm{K}$ files \#10 (Maillefer Instruments S.A, Ballaigues, Switzerland). For canal shaping, new K-flexofile files (Maillefer Instruments S.A) were used. The working length was established $1 \mathrm{~mm}$ short of the point at which a \#10 Kfile exited the apical foramen, in order to obtain an apical stop. The step-back technique was used for root canal shaping. The thinnest file that would shorten the canal walls to the previously determined extent was considered to be the first instrument. The file for recapitulation was standardized using a \#30 K-Flexofile file and the final file was a \# $55 \mathrm{~K}$-file. During instrumentation, in both groups, the canals were copiously irrigated with $1 \% \mathrm{NaOCl}$. In Group II, after shaping, the canals were also irrigated with $17 \%$ EDTA, followed by a final flush with $\mathrm{NaOCl}$. After irrigation, the canals of both groups were dried using paper points 15-40 (Dentisply Ind. e Com. Ltda, Petrópolis, RJ, Brazil) and finally obturated with lateral condensation of gutta-percha and AH plus sealer (Dentsply/DeTrey, Konstanz, Germany) beyond the apical stop. For each canal, a standardized gutta-percha cone (Dentisply Ind. e Com. Ltda) was selected according to the root canal length and diameter, preventing passage of the accessory gutta-percha points. The sealer was introduced into the root canals with a \#30 K-Flexofile file, and the standardized gutta-percha cone coated with sealer was fitted as a master cone. Lateral compaction was performed with \#25 and \#30 finger spreaders (Dyna, Bourges, France), and B7 and B8 accessory cones (Tanari, Manacapuru, AM, Brazil) were introduced to fill the root canal. Excess gutta-percha was removed with a heated instrument and cold pluggers were used to vertically condense the coronal gutta-percha.

After canal obturation, the roots were cleared. Clearing was proposed by Robertson, et al. ${ }^{11}$ (1980) to allow a threedimensional visualization of the internal tooth structure. The teeth were demineralized in $5 \%$ nitric acid until a milky color was achieved. The solution was renewed every $24 \mathrm{~h}$ until the process ended. The specimens were then dehydrated in $80^{\circ}$ ethanol for $12 \mathrm{~h}$, followed by $1 \mathrm{~h}$ in $90^{\circ}$ ethanol and 1 $\mathrm{h}$ in $96^{\circ}$ ethanol. This last procedure was repeated three times. All ethanol solutions were obtained by the dilution of $100 \%$ ethanol in distilled water. The specimens were then allowed to dry naturally for $10 \mathrm{~min}$ and were put into glass vials with methyl salicylate $\left(\mathrm{C}_{8} \mathrm{H}_{8} \mathrm{O}_{3}\right)$. After $2 \mathrm{~h}$, the internal structure of the tooth could be visualized. Lateral canals, secondary canals and apical deltas were observed under a stereomicroscope at 40x magnification (Meiji Techno Co., Ltd., Tokyo, Japan). The microscopic analysis identified the presence as well as the type of canal ramifications in both groups of teeth and allowed for their classification. These data were recorded for further comparison. The outcomes of the influence of smear layer removal on the obturation of root canal ramifications were evaluated with a twoproportion binomial test in order to compare two irrigation regimes (with and without EDTA).

\section{RESULTS}

The sample consists of 80 teeth, divided into 2 groups of 40 teeth each. Group I was irrigated with $1 \% \mathrm{NaOCl}$ and Group II with $1 \% \mathrm{NaOCl}$ followed by a final irrigation with $17 \%$ EDTA.

Table 1 presents ramifications observed in the groups, showing that smear layer removal does not interfere on the root canal ramifications obturation. In Group I (no EDTA), 5 apical deltas were found (Figure 1A), while in Group II (treated with EDTA), 3 apical deltas could be visualized. As to secondary canals, 7 ramifications were found in Group I and 8 in Group II (Figure 1B). On the other hand, when

TABLE 1- Presence of apical deltas, lateral canals and secondary canals for different irrigation regimens

\begin{tabular}{lcccc} 
& Apical Deltas & Secondary Canals & Lateral Canals & Total \\
\hline Group I & 5 & 7 & 6 & 18 \\
Group II & 3 & 8 & 4 & 15 \\
\hline
\end{tabular}




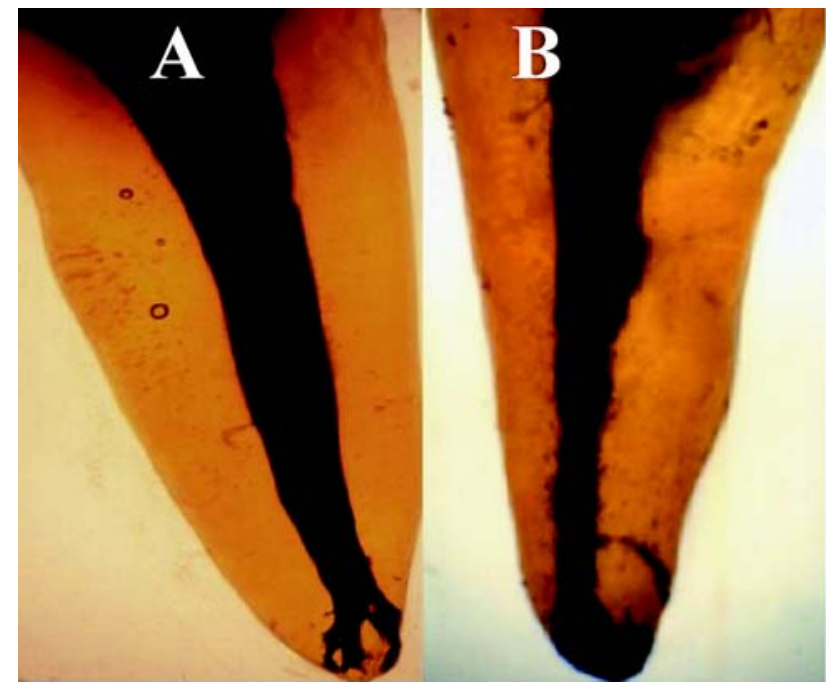

FIGURE 1- (A) Apical delta filled with $A H$ Plus sealer observed in Group I (no EDTA). (B) Secundary canal filled with AH Plus sealer after irrigation with EDTA (Group II)

lateral canals were analyzed, there were 6 occurrences in Group I and 4 in Group II.

Figure 2 shows the number of ramifications and their percentiles for Groups I and II. In Group I, 45\% of the teeth had at least one filled ramification (18 teeth). In Group II the occurrence of filled root canal ramifications was $37.5 \%$ of the sample (15 teeth).

According to the chi-square test, there were no statistically significant differences in the obturation of root canal ramifications between Groups I and II $(p=0.32)$.

\section{DISCUSSION}

The efficiency of EDTA in smear layer removal has already been proved ${ }^{6,7,15}$. It has been widely used for smear layer removal and is the most frequently used substance in studies that compare smear-covered and smear-free surfaces in achieving good root canal seal ${ }^{6,7,15}$.

White, et al. ${ }^{18}$ (1984) observed more effective results for smear layer removal when EDTA was used as a final irrigant. Vivacqua-Gomes, et al. ${ }^{17}$ (2002) observed lower infiltration as well as better apical seal for teeth irrigated with EDTA. Those findings support the advantages of removing the smear layer and indicate that EDTA is an efficient substance for this purpose. However, in the present study, the use of $17 \%$ EDTA and $\mathrm{NaOCl}$ as final irrigants after root canal shaping did not affect root canal ramification filling. The obturation of root canal ramifications can establish a connection between the main root canal and the periodontal ligament, as well as the apical foramen. Therefore, periodontal problems might be associated with necrotic and infected root canal ramifications, highlighting the importance of the capacity of the endodontic sealer to flow into these irregularities ${ }^{1}$. Although a complete seal cannot be achieved ${ }^{1,14}$, the physical presence of the sealer

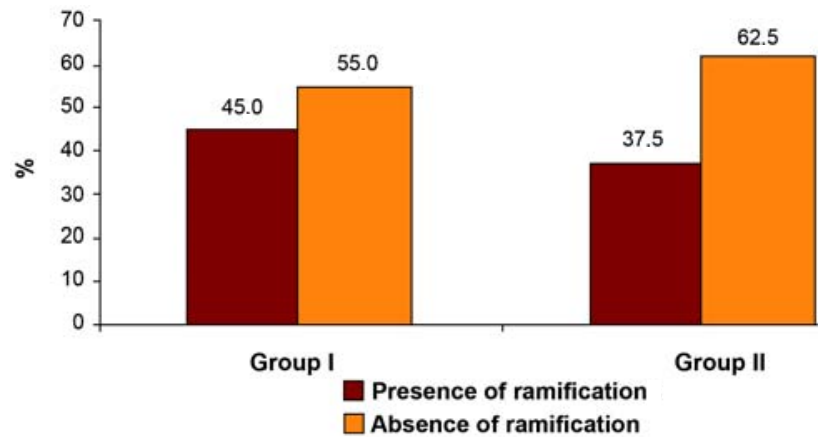

FIGURE 2- Ramifications observed in Groups I and II

and its antimicrobial property might eliminate or inhibit the growth of microorganisms in the root canal system ${ }^{13}$.

According to data available in the literature, one may infer that smear layer removal from the root canal walls is effective, clearing the entrance of the dentinal tubules and canal ramifications. However, EDTA did not act upon the depth of the dentinal material. In addition, a perfect adaptation could be observed between the cement and the filling material in the inner diameter space of the root canal in those specimens where EDTA was applied. No statistically significant difference was found in the filling of ramifications between Groups I and II.

Our findings agree with those of Villegas, et al. ${ }^{16}$ (2002) and Bertacci, et al. ${ }^{2}$ (2007). Their results did not show differences between the filling of root canal ramifications in teeth irrigated or not with EDTA. In those studies, the canals were obturated using warm gutta-percha obturation systems, while the present study used the lateral condensation technique. It may be inferred that, despite the obturation technique used, lateral canals and apical deltas can be obturated without using decalcification solutions.

On the other hand, our results disagree with those of Goldberg, et al. ${ }^{3}$ (1986). They observed that more lateral canals could be filled when $15 \%$ EDTA was used. However, those authors used radiographic images instead of clearing of the specimens and, according to Almeida, et al. ${ }^{1}$ (2007), the radiographic analysis can fail to demonstrate filled lateral and accessory canals.

Smear layer removal may be important in achieving better apical seal as well as providing a better adjustment of the filling material to the dentin walls. However, based on the results of the present study, we cannot assign to EDTA the capacity to increase the number of ramifications filled during root canal obturation.

Another issue that deserves attention is the high percentage of obturated ramifications shown in the present study. Given that a total of 33 ramifications with filling material could be observed ( $41.2 \%$ of the sample), two points should be highlighted: (1) the high prevalence of such ramifications in the root canal system; and (2) the possibility of obturating these ramifications using simple techniques that are readily available to the general dentist, such as guttapercha lateral condensation, provided that certain principles of endodontic treatment are observed, although gutta-percha 
thermoplastic techniques are more efficient in filling lateral canals (Goldberg, et al. ${ }^{4}$ 2001).

It was also seen that the internal morphology of the canines used in this study presented a larger number of secondary canals when compared to lateral canals and apical deltas. Moreover, if one were to add apical deltas to secondary canals as observed in the sample, it could be verified that the apical third is the section that presents the largest number of ramifications.

Given that the apical third is the most technically challenging region of the root canal, it is mandatory to proceed with careful instrumentation using abundant irrigation and use of intracanal medication that will act on the areas that are not accessible to instrumentation.

\section{CONCLUSIONS}

According to the present study, the use of EDTA as a final irrigant after root canal shaping does not optimize the filling of lateral canals, secondary canals and apical deltas when gutta-percha lateral condensation was the technique employed for root canal filling. There were no significant differences regarding the filling of canal ramifications when comparing irrigation with $1 \% \mathrm{NaOCl}$ and irrigation with $1 \% \mathrm{NaOCl}$ followed by irrigation with $17 \%$ EDTA and a final flush with $\mathrm{NaOCl}$.

\section{REFERENCES}

1- Almeida JFA, Gomes BPFA, Ferraz CCR, Souza-Filho JF, Zaia AA. Filling of artificial lateral canals and microleakage and flow of five endodontic sealers. Int Endod J. 2007;40:692-9.

2- Bertacci A, Baroni C, Breschi L, Venturini M, Prati C. Influence of smear layer in lateral channels filling. Clin Oral Investig. 2007;11:353-9.

3- Goldberg F, Massone JE, Spielberg C. Effect of irrigation solutions on the filling of lateral root canals. Endod Dent Traumatol. 1986;2:65-6.

4- Goldberg F, Artaza LP, De Silvio A. Effectiveness of different obturation techniques in the filling of simulated lateral canals. J Endod. 2001;27:3624.

5- Madison S, Krell KV. Comparison of ethylenediamine tetraacetic acid and sodium hypochlorite on the apical seal of endodontically treated teeth. J Endod. 1984;10:499-503.

6- Mello I, Robazza CR, Antoniazzi JH, Coil J. Influence of different volumes of EDTA for final rinse on smear layer removal. Oral Surg Oral Med Oral Pathol Oral Radiol Endod. 2008;106(5):e40-3.

7- Menezes AC, Zanet CG, Valera MC. Smear layer removal capacity of disinfectant solutions used with and without EDTA for the irrigation of canals: a SEM study. Pesqui Odontol Bras. 2003;17:349-55.

8- Miserendino LJ, Levy GC, Rizoiu IM. Effects of Nd:YAG laser on the permeability of root canal wall dentin. J Endod. 1995;21(2):83-7.

9- Oskan T, Aktener BO, Sen BH, Tezel H. The penetration of root canal sealers into dentinal tubules. A scanning electron microscope study. Int Endod J. 1993;26:301-5.
10- Putzer P, Hay H, Günay H. Highly concentrated EDTA gelimproves cleaning efficiency of root canal preparation in vitro. Clin Oral Investig. 2008;12(4):319-4.

11- Robertson D, Leeb IJ, McKee M, Brewer E. A clearing technique for study of root canal systems. J Endod. 1980;6:421-4.

12- Saleh IM, Ruyter IE, Haapasalo M, Ostravick D. Bacterial penetration along different root canal filling materials in the presence or absence of smear layer. Int Endod J. 2008;41:32-40.

13- Saleh IM, Ruyter IE, Haapasalo M, Ostravick D.Survival of Enterococcus faecalis in infected dentinal tubules after root canal filling with different root canal sealers in vitro. Int Endod J. 2004;37:193-8.

14- Tay FR, Loushine RJ, Wellwer RN. Ultrastructural evaluation of the apical seal in roots filled with a polycaprolactone-based root canal filling material. J Endod. 2005;31:514-9.

15- Teixeira CS, Felippe MC, Felippe WT. The effect of application time of EDTA and $\mathrm{NaOCl}$ on intracanal smear layer removal: a SEM analysis. Int Endod J. 2005;38:285-90.

16- Villegas JC, Yoshiuka T, Kobayashi C, Suda H. Obturation of accessory canals after four different final irrigation regimens. J Endod. 2002;28:5346.

17- Vivacqua-Gomes N, Ferraz CC, Gomes BP, Zaia AA, Teixeira FB, Souza FJ Filho. Influence of irrigants on the coronal microleakage of laterally condensed gutta-percha root fillings. Int Endod J. 2002;35:791-

18- White RR, Goldman M, Lin PS. The influence of the smear layer upon dentinal tubule penetration by endodontic filling materials. Part II. J Endod. 1987;13:369-74 